\title{
Effect of Aerobic Training on Body Mass Index on Sedentary Obese Men
}

\section{Shenbagavalli, A and Mary R. D}

Prof. and Head, Dept. of Physical Education \& Health Sciences, Alagappa University, Karaikudi. Research Scholar, Dept. of Physical Education \& Health Sciences, Alagappa University, Karaikudi

\section{Abstract}

The aim of this study was to investigate the effect of Aerobic training on Body Mass Index on sedentary obese men. Thirty obese Men were selected randomly and equally divided into two groups - Experimental group and Control group. The experimental group was administered aerobic training programme, five days in a week for a period of 8-weeks. The control group did not involve in any fitness programme or training programme. Once in 2 weeks the load was increased. The Body Mass Index (BMI) was selected as variable. The collected data were analyzed by using ' $t$ ' ratio. From the findings it is quiet interesting to know that the sedentary obese men have positive influence upon their Body Mass Index due to the training programme given. The aerobic training helped the subjects to decrease the weight and BMI. It is thus concluded that mild aerobic training can be adopted by obese men to decrease the magnitude of obesity.

Key Words: $\quad$ Body mass index, Sedentary obese, Aerobic training programme

\section{Introduction}

There has been outstanding advancement in the medical field which has taken place during the last few years, in arresting and finding cures for many incurable maladies, but obesity has so far successfully eluded most of them, as has cancer. The present generation is in constant quest for a remedy for this malady. New solutions for slimming are coming up every other day, in the form of pills and potions that are gaining entrance in many physicians consulting rooms. Many are manufacturing ultra modern drugs with tall claims of weight reducing effects.

Crash diets are experimented with varying effects (Keil, 2002 and Alison et al, 2007). Stay trim devices are being manufactured and advertised in order to lure those who wish to lose weight, to go in for a trial. Fast weight reductions have been reported to cause gall stone formations (Liddle et al, 1989, Totani, et al, 2008). Health clubs that advertise fitness and weight reducing programmes are attracting young and old from all corners. Some of these programmes are no doubt effective, but they cost too much and consume a lot of energy. Sometimes except for an over all well being, they never help reduce a single pound. Reducing weight can be a natural activity and an enjoyable pastime for those who do not suffer from any other serious disease. They can reduce by adopting a method that suits their physical, mental and psychological needs. However, the proper weight reducing remedies are those, which do not leave the individual with, any bad or undesirable after effects and at the same time have a lasting effect. Obese people, who lead a fairly comfortable and carefree life, may detect 
the very idea of having to really toil for achieving a thing like a trim figure or good health. Their mistaken conception is, that if external help is available, they can achieve better results in reducing their weight without themselves doing anything much. Through such help though some modes of treatment is available, they require the actual participation and absolute co-operation of the individual during the course of treatment. This is because unless the individual realizes that it is his responsibility to lose weight, the weight-reducing program will be a total failure.

Automation has modified the need for physical activities. Elevators, automobiles, two and four wheelers and the like have replaced walking, cycling and other natural exercises in the lives. Competition in every field has created a tendency towards more brainwork than physical work for a large group of people. They consequently take up tension-ridden jobs. Physical neglect caused by this is resulting in obesity in most cases. Aerobic exercise is recommended to lose weight. Aerobic exercise does not mean that you should work your muscles strenuously to some tune played in a recorder as it is found in many health clubs. Aerobic is a system of exercising by means of rhythmic activities. These include walking, swimming, cycling, rowing, skating and many such activities. Even rope, skipping is an aerobic exercise. The aim of such exercise is to improve fitness through increased oxygen consumption (Park et al, 2003; Wong et al, 2008). Aerobic exercise programs have been reported to improve body composition, lipid profile and lipid utilization in the body of normal and obese subjects (Blaak et al, 2002; deGlisezinski et al, 2003; Nassis et al, 2005; Okura et al, 2005;
Polak et al, 2006). Dancing to a tune and exercising the muscles is not recommended for persons suffering from complicated health problems. One should select the type of aerobic exercise that suits his need instead of doing exercises recklessly. Waking is the best aerobic exercise that even a heart patient can do. Most obese people do have at least some minor heart and lung ailments.

\section{Material and Method}

The aim of this study was to investigate the effect of aerobic training on Body Mass Index (BMI) on sedentary obese men. The investigators randomly selected 30 obese men and divided them into two groups, 15 subjects were assigned to an experimental group and 15 subjects to the control group. Prior to the administration of test, the investigators held a series of meetings with the subjects and made them clear about the objectives and purposes of the test. The testing procedure was explained to them in detail. They were requested to co-operate and participate in the training programme. BMI was selected as variable. The experimental group was administered physical training programme five days in a week for a period of 8 weeks. The control group did not involve in any fitness program or training programme.

The subjects were given warming up exercises for a period of 10 minutes before starting the training session. It included jogging, stretching, rotation at various joints, walking on heels and toes, forward bend, backward bend, sideward stretch, rotation of shoulder joints, hip joints, stretching of calf and quadriceps muscle groups.

The details of the training schedule are given below. 
Training Schedule

\begin{tabular}{lc}
\hline WEEK & TRAINING IN MINUTES \\
\hline First two weeks & 5 min. walking and 5 min. Jogging \\
\hline $3-4$ weeks & 10 min. walking and 5 min. Jogging \\
\hline $5-6$ weeks & 15 min. walking and 10 min. Jogging \\
\hline $7-8$ weeks & 30 min. walking and 20 min. Jogging \\
\hline Warm Down & 10 min.
\end{tabular}

After the training sessions the subjects were asked to go for limbering down exercises. It included slow jogging, light stretching and slow rotation exercises.

The BMI of a subject was calculated by measuring the height in meters and body weight in kilograms. The following equation was used to calculate the Body Mass Index.

$$
\mathrm{BMI}=\frac{\text { Weight }(\mathrm{kg})}{\operatorname{Height}(\mathrm{m})^{2}}
$$

A persons Body Mass Index calculation can be compared with the following ranges:

$<20$ is underweight;

20 to 25 is desirable weight,

25 to 30 is overweight;

30 to 30 is obese and

$>35$ is very obese.

To compare the mean difference between initial and final scores of experimental and control group, ' $t$ ' test was employed with Body Mass Index.

\section{Results \& Discussion}

Table 1: Mean standard deviation, standard error and ' $t$ ' ratio of Experimental and Control groups in Body weight and Body Mass Index.

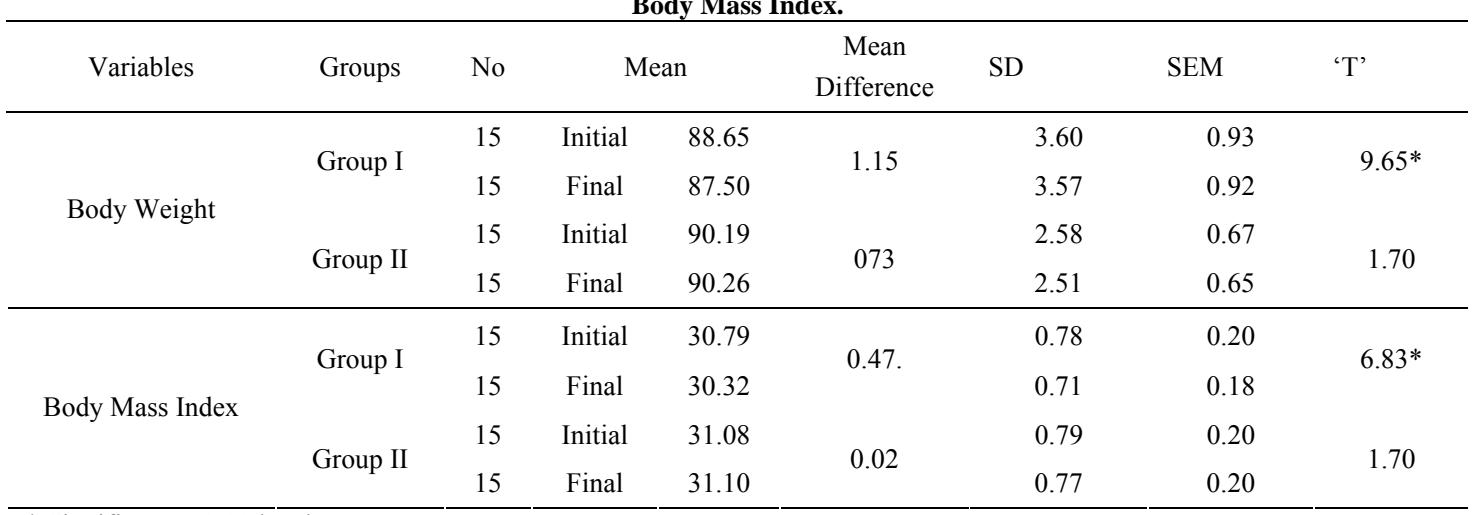

* Significant at 0.01 levels.

In Table 1, the calculated ' $t$ ' value for experimental group in the case of body weight was 9.654 which was significant in statistical terms. But in the case of control group the calculated ' $t$ ' ratio was 1.703 which was lower than the required table value. This shows that the training program resulted in a significant reduction in the body weight of experimental group. The calculated' value for experimental group in Body Mass Index was 6.826 which was higher than the required table value at 0.01 levels. But in the case of control group the calculated' $t$ ' ratio was 1.696 which was lower than the required table value. This shows that the training programe caused a significant reduction in the Body Mass Index in the experimental group.

\section{Discussion}

All the subjects of the experimental group involved in this study had undergone regular aerobic training 
programme for a period of eight weeks. From the table it was evident that in the case of Body Mass Index there were significant changes noticed after eight weeks of regular Aerobic training. As regard to control group no changes were seen in the Body Mass Index.

From the findings it is quiet interesting to know that the sedentary obese men have positive influence upon their Body Mass Index due to the training programme given. The Aerobic training helped the subjects to decrease the weight and also helped them to keep the heart healthy.

\section{Conclusion}

Participation in eight weeks of aerobic training resulted in improved in Body Mass Index.

\section{References}

Alison E. F., Austin, S. B., Taylor, C. B., Malspeis, S. and Rosner, B. 2007. Relation between Dieting and Weight Change among Preadolescents and Adolescents. Pediatrics, 112 (4): 900.

Blaak, El. E. and Saris, Wim, H. M. 2002. Substrate oxidation, obesity and exercise training. Best practice \& research. Clinical Endocrinology \& Metabolism, 16(4): $667-678$.

de Glisezinski, I / Moro, C / Pillard, F / Marion-Latard, F. et al 2003. Aerobic training improves exercise- induced lipolysis in SCAT and lipid utilization in overweight men. Endocrinology and Metabolism, 285(5): .984-990.

Keil, R. 2002. Dieting for weight reduction. Medizinische Monatsschrift für Pharmazeuten, 25(6): 217-217.

Liddle, R. A., Goldstein, R. B. and Saxton, J. 1989. Gallstone formation during weight-reduction dieting. Archives of Internal Medicine, 149(8): 1750-1753.

Nassis, G. P., Papantakou, K., Skenderi, K., Triandafillopoulou, M., Kavouras, S. A., Yannakoulia, M., Chrousos, G. P. and Sidossis, L. S. 2005 Aerobic exercise training improves insulin sensitivity without changes in body weight, body fat, adiponectin, and inflammatory markers in overweight and obese girls. Metabolism: Clinical And Experimental, 54(11): 1472-1479.

Okura, T., Nakata, Y., Lee, D. J., Ohkawara, K. and Tanaka, K. 2005. Effects of aerobic exercise and obesity phenotype on abdominal fat reduction in response to weight loss. International Journal of Obesity, 29(10): 1259-1266.

Park, S.K., Park, J.H., Kwon, Y.C., Kim, H.S., Yoon, M.S. and Park, H.T. 2003. The effect of combined aerobic and resistance exercise training on abdominal fat in obese middle-aged women. Journal Physiolog. Anthrop. and Appl. Human Science, 22(3):129-135.

Polak, J., Klimcakova, E., Moro, C. et al 2006. Effect of aerobic training on plasma levels and subcutaneous abdominal adipose tissue gene expression of adiponectin. Metabolism, 55(10): 1375-1381, Oct

Totani, N., Burenjargal, M. and Yawata, M. 2008. Effects of oil heated with gluten on weight-loss dieting. Journal of Oleo Science, 57(6): 321-326.

Wong, P. C. H. Chia, M. Y. H., Tsou, I. Y. Y., Wansaicheong, et al, 2008. Effects of a 12-week exercise training programme on aerobic fitness, body composition, blood lipids and C-reactive protein in adolescents with obesity. Annals of the Academy of Medicine, Singapore, 37(4): 286-293. 